\title{
Analisis Validasi Keterampilan Komunikasi Dan Argumentasi Siswa Biologi SMA Kelas XI MIPA
}

\author{
Wiwin Wulansari', Mumun Nurmilawati², Budhi Utami ${ }^{3}$, Eko Budi Christiono ${ }^{4}$ \\ wiwinwulansari762@gmail.com \\ Mahasiswa Program Studi Pendidikan Biologi, Universitas Nusantara PGRI Kediri \\ Dosen Program Studi Pendidikan Biologi, Universitas Nusantara PGRI Kediri2,3 \\ Guru Mata Pelajaran Biologi SMAN 1 Grogol 4
}

\begin{abstract}
In Indonesia, 21 st century education has 4 skills, namely creative thinking, critical thinking, collaboration, and communication skills. 21st Century skills are applied through the K-13 curriculum which requires students to be active in learning. It is expected that students will be able to have 21st century skills including communication and argumentation skills. Communication skills are important for students to help convey, listen and understand the meaning of knowledge, values, attitudes and attention. Argumentation skills are important for students to help them argue rationally, so that other people can accept these opinions. Instruments of communication and argumentation skills of students are made as a tool to measure student skills, and instrument of validation makes it easier to collect data with the results more complete, good, systematic and easy to process. The research instrument used was an instrument of communication skills and student argumentation. This study aims to determine the validation crite ria of communication skills and argumentation instruments for biology students of XI MIPA high school students. The method used is descriptive method. Based on the data obtained from the research results showed that the level of validation based on the experts of communication skills and argumentation of biology students in class XI MIPA high school including the criteria of Good (B) with a value of 25, whereas according to practitioners the communication skills and argumentation instruments of class XI MIPA high school students including the criteria of Very Good (SB) with a value of 26.
\end{abstract}

Keywords: Communication and argumentation skills

\begin{abstract}
Abstrak
Di Indonesia pendidikan abad 21 memiliki 4 keterampilan yaitu creative thinking (berpikirkreatif), critical thinking(berpikir kritis),collaboration (keterampilankolaborasi), dan communication(keterampilan komunikasi). Keterampilan abad 21 tersebut diwujudkan melalui kurikulum $\mathrm{K}-13$ yang menuntut siswa aktif dalam pembelajaran. Diharapkan siswa mampu memiliki keterampilan abad 21 , diantaranya keterampilan komunikasi dan argumentasi. Keterampilan komunikasi penting bagi siswauntuk membantu menyampaikan, mendengarkan dan memahami makna pengetahuan, nilai, sikap dan perhatian. Keterampilan argumentasi penting bagi siswauntuk membantu siswa berpendapat secara rasional, sehingga orang lain menerima pendapat tersebut. Instrumen keterampilan komunikasi dan argumentasi siswa dibuat sebagai alat untuk mengukur keterampilan siswa, dan validasi instrumen mempermudah pengumpulkan data dengan hasil lebih lengkap,baik, sistematis dan mudah diolah. Instrumen penelitian yang digunakan adalah instrumen keterampilan komunikasi dan argumentasi siswa. Penelitian ini bertujuan untuk mengetahui kriteria validasi instrumen keterampilan komunikasi dan argumentasi siswa biologi SMA kelas XI MIPA. Metode penelitian yang digunakan adalah metode deskriptif. Berdasarkan data hasil penelitian yang diperolehmenunjukkan bahwa tingkat validasimenurut ahli instrumen keterampilan komunikasi dan argumentasi siswa biologi SMA kelas XI MIPA termasuk kriteria Baik (B) dengan nilai 25, sedangkan menurut praktisi instrumen keterampilan komunikasi dan argumentasi siswa SMA kelas XI MIPA termasuk kriteria Sangat Baik (SB) dengan nilai 26.
\end{abstract}

Kata Kunci: keterampilan komunikasi, argumentasi

\section{PENDAHULUAN}

Menurut Baswedan (2016) dalam seminarnya bahwa di jaman revolusi industry 4.0 ada 4 keterampilan yang harus dimiliki siswa yaitu: berpikir kreatif (creativity),berpikir kritis dan menyelesaikan masalah (critical 
thinking and problem solving), keterampilan bekerja sama (ability to work collaboratively) dan keterampilan berkomunikasi (communication skills). Empat keterampilan tersebut penting untuk dimiliki individu dalam menghadapi tantangan di era digital.

Keterampilan abad 21 di Indonesia diwujudkan melalui kurikulum 2013 yang menuntut siswa aktif dalam pembelajaran. Harapannya siswa akan memiliki salah satu keterampilan abad 21 yaitu keterampilan komunikasi dan argumentasi. Sebagai makhluk sosial, individu membutuhkan orang lain, sehingga keterampilan komunikasi sangat dibutuhkan. Tak terkecuali siswa di sekolah juga harus memiliki keterampilan komunikasi untuk membantu menyampaikan, mendengarkan dan memahami makna pengetahuan, nilai, sikap dan perhatian. Keterampilan komunikasi untuk siswa diantaranya adalah keterampilan berbicara, membaca,dan menulis yang digunakan dalam interaksi sosialnya (Marfuah, 2017). Keterampilan berargumentasi menuntut seseorang untuk menyampaikan pendapatnya baik secara tertulis maupun lisan. Kemampuan argumentasi penting bagi siswa untuk membantunya mengemukakan pendapat secara rasional, sehingga pendapat siswa dapat diterima oleh orang lain.

Keterampilan komunikasi dan argumentasi dapat diketahui dengan menggunakan alat ukur berupa Instrumen penelitian. Instrumen adalah alat untuk mengumpulkan data dengan hasil yang lengkap, sistimatis dan lebih mudah diolah (Aedi, 2010). Menurut Riyani (2017) instrumen penelitian meliputi lembar observasi, tes hasil belajar, angket, pedoman wawancara, catatan lapangan, alat perekam elektronik suara, dan gambar. Ada dua macam bentuk instrumen yaitu tes untuk mengukur prestasi belajar dan nontest untuk mengukur sikap atau keterampilan. Instrumen yang digunakan dalam penelitian ini adalah lembar observasi keterampilan komunikasi dan argumentasi siswa. Observasi keterampilan komunikasi dan argumentasi siswa mengacu pada indikator aktivitas siswa dalam berkomunikasi dan berargumentasi. Instrumen observasi berupa pedoman pengamatanterkait aktivitas siswa yang kemungkinan terjadi selama proses pembelajaran, sehingga observer (pelaku observasi) bekerja sesuai dengan pedoman yang telah dibuat (Aedi, 2010).

Data dalam penelitian erat kaitannya dengan baik tidaknya instrumen penelitian yang digunakan, sehingga memerlukan adanya validasi instrumen untuk mengetahui tingkat validasi aspek yang akan diukur. Suatu instrumen dinyatakan memiliki validasi tinggi jika alat ukur dan hasil ukurnya sesuai dengan tujuan pengukurannya (Arikunto, 2010).

Berdasarkan uraian diatas perlu dilakukan sebuah penelitian terkait Analisis Validasi Keterampilan Komunikasi dan Argumentasi Siswa Biologi SMA Kelas XI MIPA.Penelitian ini bertujuan untuk mengetahui kriteria validasi instrumen keterampilan komunikasi dan keterampilan argumentasi siswa Biologi SMA Kelas XI MIPA. Penelitian ini diharapkan memberikan manfaat berupa inovasi baru dalam mata pelajaran biologi SMA dalam meningkatkan keterampilan komunikasi dan keterampilan argumentasi siswa Biologi SMA Kelas XI MIPA.

\section{METODE PENELITIAN}

Metode yang digunakan dalam penelitian ini adalah metode penelitian deskriptif. Metode penelitian ini, menghasilkan suatu produk berupa lembar observasi keterampilan komunikasi dan argumentasi siswa dan menguji kriteria validasi produk tersebut. 
Efektor, Vol. 7. No.1 Tahun 2020, Pages 42-48

Wiwin Wulansari, Mumun Nurmilawati, Budhi Utami, Eko Budi Christiono

Teknik pengumpulan data yang digunakan adalah dengan menggunakan lembar validasi instrumen keterampilan komunikasi dan lembar validasi instrumen keterampilan argumentasi. Lembar validasi tersebut diberikan kepada validator, kemudian validator akan memberikan penilaian dengan memberikan tanda centang pada alternatif pilihan masing - masing aspek, yaitu 4 = Sangat Baik (SB), 3 = Baik (B), 2 = Cukup (C) dan 1 = Kurang (K). Data dianalisis berdasarkan pendekatan Sturges, dimana setiap skor mempunyai interval yang sama. Pendekatan Sturges dapat dihitung menggunakan skor total dan skor rata - rata (Noviyanti, 2017). Dalam penelitian ini peneliti menggunakan skor total dengan kriteria sebagai berikut:

Tabel 1. Kriteria Validasi Instrumen Komunikasi dan Argumentasi

\begin{tabular}{cc}
\hline Skor Total (ST) & Kriteria \\
\hline $26<$ ST $\leq 32$ & Sangat Baik (A) \\
$20<$ ST $\leq 26$ & Baik (B) \\
$14<$ ST $\leq 20$ & Cukup (C) \\
$8<$ ST $\leq 14$ & Kurang (D)
\end{tabular}

Sumber: Modifikasi dari Noviyanti (2017)

\section{HASIL DAN PEMBAHASAN}

Validasi dalam penelitian ini termasuk kedalam jenis validasi konstruk. Wardah (2018) menyatakan bahwa validasi konstruk cocok digunakan dalam memvalidasi instrumen nontes seperti keterampilan komunikasi dan argumentasi siswa.Tujuan validasi dalam penelitian ini adalah untuk memperoleh masukan tentang kekurangan instrumen keterampilan komunikasi dan argumentasi siswa selama pembelajaran. Hasil validasi dianalisis dan digunakan untuk memperbaiki instrumen sehingga dapat meningkatkan kualitas instrumen keterampilan komunikasi dan argumentasi siswa. Validator dalam penelian ini terdiri dari validator ahli yaitu $\mathrm{Dr}$. Poppy Rahmatika Primandiri, M. Pd sebagai dosen Pendidikan Biologi UN PGRI Kediri dan validator praktisi Drs.Eko Budi Christiono sebagai guru mata pelajaran biologi SMAN 1 Grogol. Data validasi instrumen keterampilan komunikasi dan argumentasi siswa diperoleh sebagai berikut :

\section{Validasi Instrumen Komunikasi Siswa oleh Validator Ahli}

Tabel 2. Deskripsi Hasil Validasi Ahli Instrumen Komunikasi Siswa

\begin{tabular}{|c|c|c|c|c|c|}
\hline \multirow[t]{2}{*}{ No. } & \multirow[t]{2}{*}{ Aspek Validasi } & \multicolumn{4}{|c|}{ Alternatif Pilihan } \\
\hline & & SB & B & C & $\mathbf{K}$ \\
\hline 1. & $\begin{array}{l}\text { Indikator aktivitas dalam keterampilan komunikasi mencakup keterlibatan siswa } \\
\text { dalam pembelajaran }\end{array}$ & & $\sqrt{ }$ & & \\
\hline 2. & Indikator keterampilan komunikasi diuraikan dengan jelas di dalam indikator aktivitas & & $\sqrt{ }$ & & \\
\hline 3. & Kriteria keterampilan komunikasi yang digunakan sesuai dengan sistem penskoran & $\sqrt{ }$ & & & \\
\hline 4. & Kalimat dalam indikator aktivitas mudah dipahami & & $\sqrt{ }$ & & \\
\hline 5. & Kalimat dalam indikator aktivitas sederhana dan langsung ke sasaran. & & $\sqrt{ }$ & & \\
\hline 6. & Kalimat dalam indikator aktivitas tidak menjemukan untuk dibaca & & $\sqrt{ }$ & & \\
\hline 7. & Bahasa yang digunakan komunikatif & & $\sqrt{ }$ & & \\
\hline 8. & Tata bahasa yang digunakan sesuai dengan EYD & & $\sqrt{ }$ & & \\
\hline
\end{tabular}
Sumber : Modifikasi dari Wahyuni (2013)

Berdasarkan tabel deskripsi hasil validasi ahli instrumen keterampilan komunikasi siswa yang diperoleh jumlah skor 25, sehingga instrumen keterampilan komunikasi siswa memiliki kriteria Baik (B).Data dari validator 
ahli mempunyai kekurangan - kekurangan: a) kriteria penilaian sebaiknya diubah menjadi lebih sederhana dari $B$ (Baik): Jika siswa mampu menguasai 3 indikator dari 3 indikator, C (Cukup): Jika siswa mampu menguasai 2 indikator dari 3 indikator, K (Kurang): Jika siswa mampu menguasai 1 indikator dari 3 indikator, SK (Sangat Kurang ): Jika siswa tidak mampu menguasai salah satu indikator saja menjadi ya atau tidak (dikotomi). Hal ini sejalan dengan pendapat Retnawati (2016) bahwa dikotomi hanya memiliki 2 pilihan jawaban. Dikotomi dapat digunakan jika peneliti ingin menanyakan sesuatu dengan variabel yang memuat dua jawaban saja, contohnya benar atau salah,ya atau tidak, dan sebagainya; b) memperhatikan aspek pada masing - masing indikator keterampilan komunikasi agar tidak memiliki kesamaan; c) memperhatikan tata bahasa pada setiap kalimat agar tidak rancu atau bermakna ganda; d) memperhatikan dan mengetahui perbedaan indikator keterampilan komunikasi dengan indikator keterampilan argumentasi, karena masing - masing indikator keterampilan memiliki aspek yang sama, yaitu : keterampilan menjelaskan, keterampilan menyampaikan pendapat dan keterampilan mempresentasikan.

Menurut Marfuah (2017) keterampilan komunikasi meliputi proses menyampaikan, menjelaskan,mendengarkan dan memahami makna pengetahuan, nilai, sikap dan perhatiandandapat berupa lisan, bahasa non verbal dan tulisan. Komunikasi tertulis, berupa deskripsi suatu hal atau tabel, grafik, diagram yang menggambarkan proses berpikir siswa. Komunikasi lisan, berupa interaksi siswa dalam pembelajaran melaluidiskusi kelompok yang meliputi keterampilan berbicara, membaca dan menulis dalam interaksi sosial. Langkah yang direkomendasikan adalah memperbaiki kekurangan - kekurangan yang ada sesuai saran dari validator. Hasil validasi instrumen keterampilan komunikasi siswa ini, dinyatakan layak digunakan dengan revisi sesuai saran.

\section{Validasi Instrumen Komunikasi Siswa oleh Validator Praktisi}

Tabel 3. Deskripsi Hasil Validasi Praktisi Instrumen Komunikasi Siswa

\begin{tabular}{|c|c|c|c|c|c|}
\hline \multirow[t]{2}{*}{ No. } & \multirow[t]{2}{*}{ Aspek Validasi } & \multicolumn{4}{|c|}{ Alternatif Pilihan } \\
\hline & & SB & B & C & K \\
\hline 1. & $\begin{array}{l}\text { Indikator aktivitas dalam keterampilan komunikasi mencakup keterlibatan } \\
\text { siswa dalam pembelajaran }\end{array}$ & $\sqrt{ }$ & & & \\
\hline 2. & $\begin{array}{l}\text { Indikator keterampilan komunikasi diuraikan dengan jelas di dalam } \\
\text { indikator aktivitas }\end{array}$ & $\sqrt{ }$ & & & \\
\hline 3. & $\begin{array}{l}\text { Kriteria keterampilan komunikasi yang digunakan sesuai dengan sistem } \\
\text { penskoran }\end{array}$ & & & $\sqrt{ }$ & \\
\hline 4. & Kalimat dalam indikator aktivitas mudah dipahami & & $\sqrt{ }$ & & \\
\hline 5. & Kalimat dalam indikator aktivitas sederhana dan langsung ke sasaran. & & $\sqrt{ }$ & & \\
\hline 6. & Kalimat dalam indikator aktivitas tidak menjemukan untuk dibaca & $\sqrt{ }$ & & & \\
\hline 7. & Bahasa yang digunakan komunikatif & & $\sqrt{ }$ & & \\
\hline 8. & Tata bahasa yang digunakan sesuai dengan EYD & & $\sqrt{ }$ & & \\
\hline
\end{tabular}

Sumber: Modifikasi dari Wahyuni (2013)

Berdasarkan tabel deskripsi hasil validasi praktisi instrumen keterampilan komunikasi siswa yang diperoleh jumlah skor 26, sehingga instrumen keterampilan komunikasi siswa memiliki kriteria Sangat Baik (SB). Data dari validator praktisi mempunyai kekurangan - kekurangan: a) untuk lembar validasi instrumen 
keterampilan komunikasi siswa, sebaiknya lebih dispesifikkan subjeknya seperti sekolah dan kelas yang ingin digunakan sebagai subjek, karena keterampilan yang dimiliki setiap siswa berbeda sehingga mempengaruhi kondisi kelas.Hal ini sejalan dengan pendapat Noviyanti (2017) bahwa komunikasi siswa dapat mempengaruhi suasana kelas, meningkatkan kemampuan intelektual, kematangan emosional dan sosial siswa; b) kriteria penilaian pada lembar validasi kurang sesuai, sebaiknya dirubah agar rentangannya sama rata antara kriteria satu dengan lainnya, yaitu dari Sangat Baik (SB), Baik (B), Kurang (K) dan Sangat Kurang (SK) menjadi Sangat Baik (SB), Baik (B), Cukup (C) dan Kurang (K). Langkah yang direkomendasikan adalah memperbaiki kekurangan - kekurangan yang ada sesuai saran dari validator. Namun, untuk penentuan subjek baik sekolah maupun kelas, menurut penulis tidak perlu dispesifikkan karena instrumen keterampilan komunikasi siswa ini, dapat digunakan untuk menilai keterampilan komunikasi siswa di beberapa sekolah dan kelas. Kesimpulan hasil validasi instrumen keterampilan komunikasi siswa dari validator praktisi dinyatakan layak untuk digunakan dengan revisi.

\section{Validasi Instrumen Argumentasi Siswa oleh Validator Ahli}

Tabel 4. Deskripsi Hasil Validasi Ahli Instrumen Argumentasi Siswa

\begin{tabular}{|c|c|c|c|c|c|}
\hline \multirow[t]{2}{*}{ No. } & \multirow[t]{2}{*}{ Aspek Validasi } & \multicolumn{4}{|c|}{ Alternatif Pilihan } \\
\hline & & SB & B & C & K \\
\hline 1. & $\begin{array}{l}\text { Indikator aktivitas dalam keterampilan argumentasi mencakup keterlibatan } \\
\text { siswa dalam pembelajaran }\end{array}$ & & $\sqrt{ }$ & & \\
\hline 2. & $\begin{array}{l}\text { Indikator keterampilan argumentasi diuraikan dengan jelas di dalam } \\
\text { indikator aktivitas }\end{array}$ & & $\sqrt{ }$ & & \\
\hline 3. & $\begin{array}{l}\text { Kriteria keterampilan argumentasi yang digunakan sesuai dengan sistem } \\
\text { penskoran }\end{array}$ & $\sqrt{ }$ & & & \\
\hline 4. & Kalimat dalam indikator aktivitas mudah dipahami & & $\sqrt{ }$ & & \\
\hline 5. & Kalimat dalam indikator aktivitas sederhana dan langsung ke sasaran. & & $\sqrt{ }$ & & \\
\hline 6. & Kalimat dalam indikator aktivitas tidak menjemukan untuk dibaca & & $\sqrt{ }$ & & \\
\hline 7. & Bahasa yang digunakan komunikatif & & $\sqrt{ }$ & & \\
\hline 8. & Tata bahasa yang digunakan sesuai dengan EYD & & $\sqrt{ }$ & & \\
\hline
\end{tabular}

\section{Sumber : Modifikasi dari Wahyuni (2013)}

Berdasarkan tabel deskripsi hasil validasi ahli instrumen keterampilan argumentasi siswa diperoleh jumlah skor 25, sehingga instrumen keterampilan argumentasi siswa memiliki kriteria Baik (B). Data yang diperoleh dari validator ahli memiliki kekurangan - kekurangan: a) kriteria penilaian sebaiknya dirubah menjadi lebih sederhana dari B (Baik) : Jika siswa mampu menguasai 3 indikator dari 3 indikator, C (Cukup): Jika siswa mampu menguasai 2 indikator dari 3 indikator, $\mathrm{K}$ (Kurang): Jika siswa mampu menguasai 1 indikator dari 3 indikator, SK (Sangat Kurang): Jika siswa tidak mampu menguasai salah satu indikator saja menjadi ya atau tidak (dua alternatif pilihan atau dikotomi); b) memperhatikan aspek pada masing - masing indikator keterampilan argumentasi agar tidak memiliki kesamaan; c) memperhatikan tata bahasa pada setiap kalimat agar tidak rancu atau bermakna ganda; d) memperhatikan dan mengetahui perbedaan indikator keterampilan argumentasi dengan indikator keterampilan komunikasi, karena masing - masing indikator keterampilan memiliki aspek yang sama, yaitu : keterampilan menjelaskan, keterampilan menyampaikan pendapat dan keterampilan mempresentasikan. Menurut Devi (2018) keterampilan argumentasi memberikan pengetahuan pada siswa dalam 
Efektor, Vol. 7. No.1 Tahun 2020, Pages 42-48

Wiwin Wulansari, Mumun Nurmilawati, Budhi Utami, Eko Budi Christiono

berbahasa dan berpikir atau berpendapat, dalam pembelajaran siswa menangkap dan merespon pesan materi, dengan memberi tanggapan kemudian ditanggapi lagi oleh siswa lainnya.

Berdasarkan pengertian diatas, dapat disimpulkan bahwa argumentasi merupakan pendapat, pernyataan, atau sikap disertai fakta - fakta, sehingga pendapat tersebut dapat dibuktikan kebenaranya. Langkah yang direkomendasikan adalah memperbaiki kekurangan - kekurangan yang ada sesuai saran dari validator. Hasil validasi instrumen keterampilan argumentasi siswa ini, dinyatakan layak digunakan dengan revisi sesuai saran.

Validasi Instrumen Argumentasi Siswa oleh Validator Praktisi

Tabel 5. Deskripsi Hasil Validasi Praktisi Instrumen Argumentasi Siswa

\begin{tabular}{|c|c|c|c|c|c|}
\hline \multirow[t]{2}{*}{ No. } & \multirow[t]{2}{*}{ Aspek Validasi } & \multicolumn{4}{|c|}{ Alternatif Pilihan } \\
\hline & & SB & B & C & $\mathrm{K}$ \\
\hline 1. & $\begin{array}{l}\text { Indikator aktivitas dalam keterampilan argumentasi mencakup keterlibatan } \\
\text { siswa dalam pembelajaran }\end{array}$ & $\sqrt{ }$ & & & \\
\hline 2. & $\begin{array}{l}\text { Indikator keterampilan argumentasi diuraikan dengan jelas di dalam } \\
\text { indikator aktivitas }\end{array}$ & $\sqrt{ }$ & & & \\
\hline 3. & $\begin{array}{l}\text { Kriteria keterampilan argumentasi yang digunakan sesuai dengan sistem } \\
\text { penskoran }\end{array}$ & & & $\sqrt{ }$ & \\
\hline 4. & Kalimat dalam indikator aktivitas mudah dipahami & & $\sqrt{ }$ & & \\
\hline 5. & Kalimat dalam indikator aktivitas sederhana dan langsung ke sasaran. & $\sqrt{ }$ & & & \\
\hline 6. & Kalimat dalam indikator aktivitas tidak menjemukan untuk dibaca & & $\sqrt{ }$ & & \\
\hline 7. & Bahasa yang digunakan komunikatif & & $\sqrt{ }$ & & \\
\hline 8. & Tata bahasa yang digunakan sesuai dengan EYD & & $\sqrt{ }$ & & \\
\hline
\end{tabular}

Sumber : Modifikasi dari Wahyuni (2013)

Berdasarkan tabel deskripsi hasil validasi praktisi instrumen keterampilan argumentasi siswa diperoleh jumlah skor 26, sehingga instrumen keterampilan komunikasi siswa memiliki kriteria Sangat Baik (SB). Data dari validator praktisi memiliki kekurangan - kekurangan: a) untuk lembar validasi instrumen keterampilan argumentasi siswa, sebaiknya lebih dispesifikkan subjeknya seperti sekolah dan kelas yang ingin digunakan sebagai subjek, karena keterampilan yang dimiliki setiap siswa berbeda sehingga mempengaruhi kondisi kelas. Hal ini sejalan dengan pendapat Agusni (2017) bahwa argumentasi siswa dapat mempengaruhi siswa lainnya, sehingga kondisi kelas dan peran guru dibutuhkan untuk membimbing siswa mencari bukti atau fakta yang dapat memantapkan pemahaman siswa; b) kriteria penilaian pada lembar validasi kurang sesuai, sebaiknya dirubah agar rentangannya sama rata antara kriteria satu dengan lainnya, yaitu dari Sangat Baik (SB), Baik (B), Kurang (K) dan Sangat Kurang (SK) menjadi Sangat Baik (SB), Baik (B), Cukup (C) dan Kurang (K). Langkah yang direkomendasikan adalah memperbaiki kekurangan - kekurangan yang ada sesuai saran dari validator. Namun, untuk penenentuan subjek baik sekolah maupun kelas, menurut penulis tidak perlu dispesifikkan karena instrumen keterampilan argumentasi siswa ini, dapat digunakan untuk menilai keterampilan argumentasi siswa di beberapa sekolah dan kelas. Kesimpulan hasil validasi instrumen keterampilan argumentasi siswa dari validator praktisi dinyatakan layak untuk digunakan dengan revisi. 
Efektor, Vol. 7. No.1 Tahun 2020, Pages 42-48

Wiwin Wulansari, Mumun Nurmilawati, Budhi Utami, Eko Budi Christiono

\section{SIMPULAN}

Berdasarkan hasil penelitian yang telah dilakukan, dapat disimpulkan sebagai berikut: 1) Validasi ahli instrumen keterampilan komunikasi dan argumentasi siswa memiliki nilai yang sama yaitu 25 dengan kriteria Baik (B). 2) Validasi praktisi instrumen keterampilan komunikasi dan argumentasi siswa memiliki nilai yang sama yaitu 26 dengan kriteria Sangat Baik (SB). Saran yang dapat diberikan terkait penelitian ini adalah perlu dilakukan penelitian mengenai pengimplementasian instrumen keterampilan komunikasi dan argumentasi siswa dalam pembelajaran, sehingga dapat diperoleh data yang lebih akurat terkait keterampilan komunikasi dan argumentasi siswa.

\section{DAFTAR RUJUKAN}

Aedi, Nur. 2010. Instrumen Penelitian dan Pengumpulan data. ejournal.upi.edu. 5 (2) : 6 - 8

Agusni, Hendika Prasetyo. 2017. Pengaruh Skill Argumentasi Menggunakan ModelPembelajaran Problem Based Learning (PBL)Terhadap Hasil Belajar Siswa SMP. Jurnal.fkip.unila.ac.id. 5 (10) :24 - 25.

Arikunto, Suharsimi. 2010. Prosedur Penelitian Pendekatan Praktik. Jakarta: Rineka Cipta.

Devi Cahya, N. D., Susanti, Elvi. dan Indriyanti, N. Y. 2018. Analisis Kemampuan Argumentasi Siswa SMA Pada Materi Larutan Penyangga. JKPK (Jurnal Kimia Dan Pendidikan Kimia). 3 (3) : 152 - 159.

Kemendikbud. 2016. Seminar Education Transformation and 21st Century Learning di Graha Utama. URL:https://www.kemdikbud.go.id/main/blog/2016/01/teknologiinfomasi-dan-komunikasipentinguntukproses-pembelajaran-masa kini.Diakses pada 6 Desember 2019

Marfuah. 2017. Meningkatkan Keterampilan Komunikasi Peserta Didik melalui Model Pembelajaran Kooperatif Tipe Jigsaw. Jurnal Pendidikan IImu Sosial (JPIS). 26 (2) : 149 - 159.

Noviyanti, M. 2017. Kemampuan Komunikasi Matematis Siswa SMP Kanisius Gayam Yogyakarta Kelas VII C dalam Konteks Operasi Hitung Bentuk Aljabar. Jurnal repository.usd.ac.id. 3 (2) : 50 - 60

Retnawati, Heri. 2016. Analisis Kuantitatif Instrumen Penelitian (Panduan Peneliti, Mahasiswa, dan Psikometrian). Yogyakarta: Parama Publishing.

Riyani, Rizki., Maizora, Syafdi., dan Hanifah. 2017. Uji Validitas Pengembangan Tes Untuk Mengukur Kemampuan Pemahaman Relasional Pada Materi Persamaan Kuadrat Siswa Kelas VIII SMP. Jurnal Penelitian Pembelajaran Matematika Sekolah (JP2MS). 1 (1) : 1 - 6

Wahyuni, Ari. 2013. Upaya Meningkatkan Kemampuan Argumentasi Siswa.respository.ump.ac.id. 7 (1) : 7 - 32.

Wardah, Faiqotul. 2018. Pengembangan Instrumen Authentic Assessment Berupa Penilaian Proyek Untuk Mengukur Kompetensi Keterampilan Siswa. Jurnalpai.uinsby.ac.id. 6 (2) : 38 - 40. 